\title{
Laparoscopic Gastric Sleeve and Micronutrients Supplementation: Our Experience
}

\author{
D. Capoccia, ${ }^{1}$ F. Coccia, ${ }^{1}$ F. Paradiso, ${ }^{1}$ F. Abbatini, ${ }^{2}$ \\ G. Casella, ${ }^{2}$ N. Basso, ${ }^{2}$ and F. Leonetti ${ }^{1}$ \\ ${ }^{1}$ Department of Clinical Sciences, Sapienza University of Rome, Policlinico Umberto I, 00161 Rome, Italy \\ ${ }^{2}$ Surgical-Medical Department for Digestive Diseases, Sapienza University of Rome, Rome, Italy
}

Correspondence should be addressed to D. Capoccia, danilacapoccia@yahoo.it

Received 12 December 2011; Accepted 4 January 2012

Academic Editor: Francesco Saverio Papadia

Copyright (C) 2012 D. Capoccia et al. This is an open access article distributed under the Creative Commons Attribution License, which permits unrestricted use, distribution, and reproduction in any medium, provided the original work is properly cited.

Background. Laparoscopic gastric sleeve (LGS) has been recently introduced as a stand-alone, restrictive bariatric surgery. Theoretically, LGS attenuates micronutrients deficiencies and associated complications that were typically observed following malabsorptive procedures. The aim of this study was to assess some micronutrients and mineral deficiencies in patients undergoing LGS. Methods. In the period between July 2008 and April 2010, 138 obese patients (110 females and 28 males) with mean BMI $44.4 \mathrm{~kg} / \mathrm{m}^{2} \pm 6.5$, mean age $43.9 \pm 10.9$ years were enrolled and underwent LGS. Patients were followed up with routine laboratory tests and anthropometric measurements and assessed for nutritional status, as regards vitamin B12, folic acid, iron, hemoglobin, calcium, and vitamin D, every three months throughout 12 months. Results. 12 months after sleeve, patients did not show iron deficiency and/or anemia; plasma calcium levels were in the normal range without supplementation from the sixth month after the operation. Vitamin B12 and folic acid were adequately supplemented for all the follow-up period. Vitamin D was in suboptimal levels, despite daily multivitamin supplementation. Conclusion. In this study, we showed that LGS is an effective surgery for the management of morbid obesity. An adequate supplementation is important to avoid micronutrients deficiencies and greater weight loss does not require higher dosage of multivitamins.

\section{Introduction}

Obesity, traditionally defined as a body mass index (BMI) above $30 \mathrm{~kg} / \mathrm{m}^{2}$, increases the risk of death from any cause. There is currently a global pandemic of obesity and obesity comorbidities: nearly 75\% of Americans have a BMI > $25 \mathrm{~kg} / \mathrm{m}^{2}$ and 1 of 4 children are overweight or heavier [1]. The comorbidities of obesity per se and the atherosclerotic diseases they engender reduce life expectancy of obese, in particular morbidly obese, females by 7 years and males by 9 years [2].

Obese patients have a history of repeated failures after traditional methods of weight loss, such as dieting, exercise, and medications. In this context, the number of obese people who have sought bariatric surgery to treat obesity has increased since this type of surgery has been established as a key to successful weight loss and weight maintenance.

Bariatric surgery, actually considered the highest successful treatment for obesity, requires adherence to special dietary recommendations and adequate vitamins supplementations to insure the achievement of weight loss goals, weight maintenance, and correct nutritional status.

All types of bariatric surgery lead to an important decrease of ingested calories, ranging from 700 to $900 \mathrm{kcal} / \mathrm{die}$, especially during the first six months after the procedure [3]. Micronutrients deficiency is an important complication associated with bariatric surgery with $50 \%$ of cases of vitamin deficiency being observed at the end of the first postopesrative year, possibly arising from the substantial decrease of food intake from food intolerance and from dysabsorption [4].

Laparoscopic gastric sleeve (LGS) is a relatively new bariatric procedure. It was initially introduced as either the restrictive component of biliopancreatic diversion with duodenal switch (BPD-DS) or the first step of a staged approach for weight loss. In the latter, superobese patients with increased operative risks undergo LGS to initiate enough 
weight loss to allow for a second stage gastric bypass or BPDDS [5]. It has been recently used as a definitive bariatric surgery following reports of significant reduction in body mass index (BMI) and comorbidities [6]. LGS is considered a restrictive bariatric procedure, in which the fundus and the greater curvature of the stomach are removed, leaving a narrow gastric tube or "sleeve." The small intestine is neither bypassed nor removed during this procedure, minimizing the micronutritional deficiencies typically observed after malabsorptive procedures $[6,7]$.

Objectives of this study are threefold: first, to analyze if the weight loss achieved 12 months after LGS was responsible of important nutritional deficiencies; second, to examine if eventual nutritional deficiencies were related to the entity of weight loss; third, to determine whether constant daily vitamin supplementation would be sufficient to prevent possible vitamin deficiencies in obese patients after LGS.

\section{Materials and Methods}

In the period between July 2008 and April 2010, 138 obese patients (110 females and 28 males) with mean BMI $44.4 \mathrm{~kg} / \mathrm{m}^{2} \pm 6.5$, mean age $43.9 \pm 10.9$ years were enrolled and underwent LGS. Patients were followed up with routine laboratory tests and anthropometric measurements and assessed for nutritional status every three months throughout 12 months. All the patients were subdivided into five groups according to BMI: Group A with BMI between 32 and 34.9 (7 patients, 6 females and 1 male, mean BMI $32.5 \mathrm{~kg} / \mathrm{m}^{2} \pm 3.1$, mean age $36.7 \pm 13.2$ years); Group $B$ with BMI between 35 and 39.9 (29 patients, 24 females and 5 males, mean BMI $37.8 \mathrm{~kg} / \mathrm{m}^{2} \pm 1.5$, mean age $43.6 \pm$ 10 years); Group $C$ with BMI between 40 and 44.9 (40 patients, 29 females and 11 males, mean BMI $42.5 \mathrm{~kg} / \mathrm{m}^{2} \pm$ 1.6 , mean age $44.4 \pm 9.6$ years); Group $D$ with BMI between 45 and 49.9 (33 patients, 26 females and 7 males, mean BMI $46.8 \mathrm{~kg} / \mathrm{m}^{2} \pm 1.5$, mean age $45.1 \pm 12.8$ years); Group $E$ with BMI $\geq 50$ (29 patients, 25 females and 4 males, mean BMI $53.9 \mathrm{~kg} / \mathrm{m}^{2} \pm 3.2$, mean age $43.7 \pm 10.8$ years). In all the groups, for each patient, $\Delta$ weight was defined as the difference between mean weight present at baseline and mean weight detected 12 months after LGS. Then, mean $\Delta$ weight values of the five groups were compared with each other.

In addition a nutritional status assessment was detected at each follow-up visit with the blood measurement of haemoglobin, iron, ferritin, calcium, vitamin B12 and folic acid.

All patients were supplemented after LGS administering oral multivitamins in the amount of one tablet per day for the first six months. Each tablet principally contains $2,5 \mathrm{mcg}$ of vitamin B12, $200 \mathrm{mcg}$ of folic acid, $5 \mathrm{mg}$ of iron, $162 \mathrm{mg}$ of calcium, and $5 \mathrm{mcg}$ of vitamin $\mathrm{D}$, in association with other minerals and micronutrients. After this period, oral multivitamins were stopped, and one vial of intramuscular vitamin B12 (1000 mcg per month), oral vitamin $\mathrm{D}$ (0.625 mg per month) and one tablet of folic acid (5 mg per day for ten days a month) were administered during all the follow-up period.
The study has been approved by the Institutional Ethical Committee. An informed consent was given by all patients.

2.1. Surgical Technique. LGS was performed according to the technique previously described by Moy et al. [8]. From 2002, technical modifications have been introduced. The technique used in this patient group is described as follows. The patient is positioned in $30^{\circ}$ anti-Trendelenburg position with legs abducted. Five trocars are used ( 4 trocars $12 \mathrm{~mm}$ and 1 trocar $5 \mathrm{~mm}$ ). The skeletonisation of the greater curvature of the stomach started at $6 \mathrm{~cm}$ from the pylorus up to the angle of His, using a radiofrequency device. A $48 \mathrm{Fr}$ transoral bougie was positioned from the hiatus to the duodenum along the lesser curvature. The SG was performed using a linear stapler (EndoGIA, US Surgical Norwalk, CT, USA), with 2 sequential $4.8 / 60 \mathrm{~mm}$ green cartridge load firings for the antrum, and $3.5 / 60 \mathrm{~mm}$ blue cartridge for corpus and fundus or Echelon stapler with gold cartridge. The first and second cartridges of stapler are fired using the right hypochondrial trocar and the subsequent through the left subcostal port. A $60 \mathrm{~mL}$ capacity gastric pouch was finally obtained. The capacity is measured by the methylene blue dye test.

There is not agreement in the literature about the bougie size and the distance from pylorus where the gastric resection should be initiated. But in our experience, meticulous gastric fundus dissection, accurate placement of the bougie against the lesser curve, and stretching of the gastric walls during the resection are the most important factors in determining the capacity of gastric remnant.

The specimen was extracted directly through the right subcostal trocar site and the trocar sites closed by using the Bercy needle when blade trocar is positioned to avoid trocar site hernia [9].

\section{Results}

The mean postoperative BMI at 18-month follow-up was markedly decreased in all the groups as expressed in Table 1. $\Delta$ weight was higher in patients characterized by a greater BMI at baseline $(P<0.05)$. Furthermore, whereas before surgery the extreme groups $\mathrm{A}$ and $\mathrm{E}$ differed each other by 21.4 points of BMI, after 18 months this difference was significantly reduced to 13 points. Weight loss was more important in groups with higher BMI before surgery. Otherwise, in patients with lower BMI, $\Delta$ weight was $25 \mathrm{Kg}$ in the 12 month follow-up period and patients have never reached an underweight condition. At 12 months of follow-up, plasma values of haemoglobin, iron, ferritin, calcium, vitamin B12, and folic acid were not significantly different from baseline values in all patients (Table 2). Also analyzing group by group (Tables 3, 4, and 5), there were not significant differences of the nutritional parameters between values observed at baseline and the same values detected after surgery. The same vitamin and mineral supplementation ensured a correct nutritional status in all groups, even in patients who loosed 50 kilograms during this period. 
TABLE 1: BMI and weight before and after 12 months.

\begin{tabular}{lcccccc}
\hline Group & No patients & $\begin{array}{c}\text { BMI before } \\
\left(\mathrm{kg} / \mathrm{m}^{2}\right)\end{array}$ & $\begin{array}{c}\text { BMI after } \\
\left(\mathrm{kg} / \mathrm{m}^{2}\right)\end{array}$ & Weight before & Weight after & $\Delta$ weight $(\mathrm{Kg})$ \\
\hline A & 7 & $32.5 \pm 3.1$ & $22.5 \pm 3.4$ & $89.8 \pm 13.8$ & $62.5 \pm 17.5$ & 27.3 \\
B & 29 & $37.8 \pm 1.5$ & $26.1 \pm 2.4$ & $104.6 \pm 11.6$ & $72.8 \pm 13.3$ & 31.8 \\
C & 40 & $42.5 \pm 1.6$ & $29.0 \pm 2.8$ & $118.6 \pm 13.4$ & $81.5 \pm 11.1$ & 37.1 \\
D & 33 & $46.8 \pm 1.5$ & $32.3 \pm 4.1$ & $127.8 \pm 14.7$ & $89.9 \pm 12.9$ & 37.9 \\
E & 29 & $53.9 \pm 3.2$ & $35.5 \pm 4.5$ & $145.0 \pm 16.8$ & $95.9 \pm 11.6$ & 49.1 \\
\hline
\end{tabular}

TABLE 2: Nutritional parameters before and after 12 months in all the patients.

\begin{tabular}{lccc}
\hline & At baseline & 12 months after LGS & \\
\hline $\mathrm{Hb}(\mathrm{g} / \mathrm{dL})$ & $13.7 \pm 1.8$ & $13.1 \pm 3.29$ & $\mathrm{Ns}$ \\
$\mathrm{Iron}(\mu \mathrm{g} / \mathrm{dL})$ & $78.1 \pm 29.0$ & $95.9 \pm 36.6$ & $\mathrm{Ns}$ \\
Vitamin B12 $(\mathrm{pg} / \mathrm{mL})$ & $495.7 \pm 262.5$ & $488.9 \pm 229$ & $\mathrm{Ns}$ \\
Folic Acid $(\mathrm{ng} / \mathrm{mL})$ & $5.7 \pm 2.3$ & $8.7 \pm 3.9$ & $\mathrm{Ns}$ \\
Calcium $(\mathrm{mg} / \mathrm{dL})$ & $9.2 \pm 0.4$ & $9.4 \pm 0.5$ & $\mathrm{Ns}$ \\
Vitamin D $(\mathrm{ng} / \mathrm{mL})$ & $20.9 \pm 7.7$ & $20.4 \pm 10.9$ & $\mathrm{Ns}$ \\
\hline
\end{tabular}

TABLE 3: Haemoglobin ( $\mathrm{Hb})$ and iron before and after surgery.

\begin{tabular}{|c|c|c|c|c|}
\hline \multirow{2}{*}{ Group } & \multicolumn{2}{|c|}{$\mathrm{Hb}(\mathrm{gr} / \mathrm{dL})$} & \multicolumn{2}{|c|}{ Iron $(\mu \mathrm{g} / \mathrm{dL})$} \\
\hline & Baseline & $\begin{array}{l}12 \text { months } \\
\text { after LGS }\end{array}$ & Baseline & $\begin{array}{l}12 \text { months } \\
\text { after LGS }\end{array}$ \\
\hline A & $12.8 \pm 0.8$ & $13.1 \pm 1.2$ & $76.9 \pm 16$ & $97.2 \pm 58.7$ \\
\hline B & $13.4 \pm 1.5$ & $13.0 \pm 1.5$ & $67.8 \pm 22.9$ & $91.9 \pm 38.5$ \\
\hline $\mathrm{C}$ & $13.9 \pm 1.1$ & $13.2 \pm 1.5$ & $82.4 \pm 35.1$ & $87.3 \pm 38.0$ \\
\hline $\mathrm{D}$ & $13.2 \pm 1.4$ & $13.2 \pm 1.1$ & $80.1 \pm 27.5$ & $94.8 \pm 31.7$ \\
\hline $\mathrm{E}$ & $12.8 \pm 2.9$ & $13.8 \pm 6.9$ & $64.3 \pm 25.5$ & $97.4 \pm 36.4$ \\
\hline
\end{tabular}

TABLE 4: Vitamin B12 and folic acid before and after surgery.

\begin{tabular}{|c|c|c|c|c|}
\hline \multirow{2}{*}{ Group } & \multicolumn{2}{|c|}{ Vitamin B12 (pg/mL) } & \multicolumn{2}{|c|}{ Folic acid $(\mathrm{ng} / \mathrm{mL})$} \\
\hline & Baseline & $\begin{array}{l}12 \text { months } \\
\text { after LGS }\end{array}$ & Baseline & $\begin{array}{l}12 \text { months } \\
\text { after LGS }\end{array}$ \\
\hline $\bar{A}$ & $430 \pm 180$ & $459 \pm 385.4$ & $6.3 \pm 2.2$ & $7.2 \pm 3.9$ \\
\hline B & $387.5 \pm 255.7$ & $474 \pm 261.9$ & $4 \pm 1.9$ & $7.0 \pm 2.1$ \\
\hline $\mathrm{C}$ & $510.5 \pm 268$ & $364 \pm 161.2$ & $7 \pm 0.1$ & $6.7 \pm 2.6$ \\
\hline $\mathrm{D}$ & $701 \pm 258.8$ & $385.3 \pm 209.1$ & $6 \pm 2.1$ & $8.8 \pm 6.0$ \\
\hline $\mathrm{E}$ & $350.7 \pm 300.1$ & $411.2 \pm 253.4$ & $6.1 \pm 3.7$ & $5.7 \pm 2.7$ \\
\hline
\end{tabular}

TABLE 5: Calcium and vitamin D before and after surgery.

\begin{tabular}{lcccc}
\hline Group & \multicolumn{2}{c}{ Calcium $(\mathrm{mg} / \mathrm{dL})$} & \multicolumn{2}{c}{ Vitamin D $(\mathrm{ng} / \mathrm{mL})$} \\
12 months & Baseline & $\begin{array}{c}\text { 12 months } \\
\text { after LGS }\end{array}$ \\
\hline A & $9.2 \pm 0.3$ & $9.3 \pm 0.5$ & $18.5 \pm 3.6$ & $20.6 \pm 4.6$ \\
B & $9.2 \pm 0.5$ & $9.1 \pm 0.4$ & $17.1 \pm 5.4$ & $21.6 \pm 5.3$ \\
C & $9.2 \pm 0.4$ & $9.2 \pm 0.5$ & $15.9 \pm 6.7$ & $21.2 \pm 12.1$ \\
D & $9.3 \pm 0.3$ & $9.5 \pm 0.5$ & $16.4 \pm 0.9$ & $20.4 \pm 6.4$ \\
E & $9.2 \pm 0.4$ & $9.3 \pm 0.5$ & $16.4 \pm 2.3$ & $19.9 \pm 5.2$ \\
\hline
\end{tabular}

\section{Discussion}

Micronutrient deficiencies are important complications associated with bariatric surgery, with $50 \%$ of reported vitamins deficiencies occurring within the first year of surgery [10]. LGS is gaining popularity among laparoscopic bariatric surgeons. It is easy to perform and results in significant weight loss with a lower mortality than gastric bypass surgery [11]. It has been suggested that LGS has a minimal impact on macronutrients as it does not alter the site of their absorption in the small intestine [12].

Gehrer et al. compared the nutritional deficiencies occurring after LGS and laparoscopic Roux-en-Y gastric bypass (RYGB) and observed nutritional deficiencies in 57\% of patients. In particular, after LGS the following deficiencies were observed: folate in 22\%, iron 18\%, vitamin B12 in 18\% [13].

A significant number of patients developed vitamin B12 deficiency after LGS. This complication could be attributed to fundus resection, which is the most abundant part of the stomach with parietal cells that release intrinsic factor essential for vitamin B12 absorption. Also, PPIs (proton pump inhibitors) use might have played an additive role in the development of vitamin B12 deficiency in these patients by reducing acidity as demonstrated by multiple studies in nonbariatric patients [14].

In the present study the initial oral daily administration for the first 6 months and subsequent monthly administration of the intramuscular vitamin B12 are sufficient to prevent the development of vitamin B12 deficiency in our patients. Even in patients with the greater weight loss, the same dose of vitamin maintains adequate levels of vitamin B12.

Folate can be absorbed throughout the intestine, especially in the jejunum, and therefore folate deficiency is less common after LGS, usually resulting from a low intake [1517]. A very small amount of folate is stored by the body and 
a constant supply of a diet containing foods that are sources of folic acid is necessary to maintain serum concentrations. The best sources of folate are viscera, beans, and green leafy vegetables.

Some investigators have reported that low folate levels reflect nonadherence to multivitamin supplementation because the amount of supplemented folic acid properly corrects low serum folate levels.

Hakeam et al. reported folate deficiency after surgery and though patients in this study received a daily supplement containing $0.2 \mathrm{mg}$ folic acid following LGS, folate levels deteriorated throughout the study period. Therefore, patients undergoing LGS might require more than the RDA of folic acid to maintain normal folate levels. This could be attributed to the diet changes after surgery [18].

In fact, in our study, patients received daily administration containing $0.2 \mathrm{mg}$ folic acid for 6 months after LGS and $5 \mathrm{mg}$ per day for ten days a month in the subsequent period, maintaining adequate levels of folic acid.

Also, more attention has to be directed to folic acid and vitamin B12 in females planning to get pregnant after LGS, as folic acid and vitamin B12 deficiency during pregnancy in general population has been linked to the increased risk of neonatal neural tube defects.

As regards iron deficiency, Skroubis et al. demonstrated that 1-year postgastric bypass, the percentage of low ferritin and anemia increased from $18 \%$ to $32 \%$ and from $16.4 \%$ to $23 \%$, respectively [19]. Similarly, Vargas-Ruiz et al. showed that the incidence of anemia increased from $10 \%$ to $26.6 \%$ after 1 year following gastric bypass [12]. Both studies reported that study participants had received a multivitamin, plus minerals. Moreover, each of these studies had included patients with preoperative iron deficiencies, anemia, or both. Therefore, it is important to determine the accurate incidence of iron deficiency prior to surgery in order to exclude anemia caused by surgery.

As regards LGS, Hakeam et al., found a low incidence of iron deficiency $(4,9 \%)$ and of anemia (1.6\%) 12 months after surgery [18].

In this study, we did not observe iron deficiency 12 months after LGS, contrary to what was found in previous reports in which iron deficiency regarded other types of bariatric surgeries. All the patients in our study were given an iron supplementation in a multivitamin formula in amount of $5 \mathrm{mg}$ per day only for the first six months, and patients did not develop an iron deficiency during all the study period. Then, LGS seems not to be responsible for iron deficiency and/or anemia.

Bone metabolism can change during the first year after LGS. Part of this change is explained by the weight loss itself due to the loss of pressure on the weight bearing bones, thus losing a potent stimulant for bone preservation. Furthermore, normal levels of vitamin D are essential for an adequate intestinal calcium uptake. A shortage in vitamin $\mathrm{D}$ eventually leads to a negative calcium balance and causes a compensatory rise in PTH to promote bone resorption [20]. Aarts et al. reported normal calcium levels 1 year after LGS, but suboptimal levels of vitamin D, althoughout daily multivitamin supplementation.
In our study, plasma calcium levels remained in the normal range in all the patients, regardless of weight loss degree. Plasma levels of vitamin D were low before surgery in all the groups. They remained under normal range after surgery, despite patients were supplemented for all the follow-up period.

\section{Conclusions}

In this study, we showed that LGS is an effective surgery for the management of morbid obesity. An adequate supplementation is important to avoid micronutrients deficiencies and greater weight loss does not require higher dosage of multivitamins.

After 1 year, the impact of this bariatric surgery on iron indices was negligible. Therefore, iron supplementation appears unnecessary in nonanemic patients undergoing LGS at least in the interval of 6-12 months after surgery.

Close monitoring of vitamin B12 and folate levels is important and an adequate supplementation is necessary to maintain these parameters in the normal range for all the follow-up period.

Calcium supplementation is important in the first 6 months in the multivitamin formula and it is sufficient to maintain normal plasma values in all the follow-up period.

Vitamin D supplementation of $0.625 \mathrm{mg}$ per month is not sufficient to ensure adequate plasma levels.

In conclusion, we can assert that each bariatric surgical procedure needs to be assessed on the micronutrients to avoid either low or high concentrations in short and long postsurgery followup.

\section{References}

[1] H. Buchwald, S. Ikramuddin, R. B. Dorman, J. L. Schone, and J. B. Dixon, "Management of the metabolic/bariatric surgery patient," American Journal of Medicine, vol. 124, no. 12, pp. 1099-1105, 2011.

[2] K. R. Fontaine, D. T. Redden, C. Wang, A. O. Westfall, and D. B. Allison, "Years of life lost due to obesity," Journal of the American Medical Association, vol. 289, no. 2, pp. 187-193, 2003.

[3] M. Bavaresco, S. Paganini, T. P. Lima et al., "Nutritional course of patients submitted to bariatric surgery," Obesity Surgery, vol. 20, no. 6, pp. 716-721, 2010.

[4] S. P. Donadelli, M. V. M. Junqueira-Franco, C. A. de Mattos Donadelli et al., "Daily vitamin supplementation and hypovitaminosis after obesity surgery," Nutrition, vol. 28, no. 4, pp. 391-396, 2012.

[5] G. Silecchia, C. Boru, A. Pecchia et al., "Effectiveness of laparoscopic sleeve gastrectomy (first stage of biliopancreatic diversion with duodenal switch) on co-morbidities in super-obese high-risk patients," Obesity Surgery, vol. 16, no. 9, pp. 11381144, 2006.

[6] A. Baltasar, C. Serra, N. Perez et al., "Laparoscopic gastric sleeve: a multi purpose bariatric operation," Obesity Surgery, vol. 15, pp. 1124-1128, 2005.

[7] A. Iannelli, R. Dainese, T. Piche, E. Facchiano, and J. Gugenheim, "Laparoscopic sleeve gastrectomy for morbid obesity," World Journal of Gastroenterology, vol. 14, no. 6, pp. 821-827, 2008. 
[8] J. Moy, A. Pomp, G. Dakin, M. Parikh, and M. Gagner, "Laparoscopic sleeve gastrectomy for morbid obesity," American Journal of Surgery, vol. 196, no. 5, pp. e56-e59, 2008.

[9] G. Casella, E. Soricelli, A. Fantini, and N. Basso, "A timesaving technique for specimen extraction in sleeve gastrectomy," World Journal of Surgery, vol. 34, no. 4, pp. 765-767, 2010.

[10] S. S. Malinowski, "Nutritional and metabolic complications of bariatric surgery," American Journal of the Medical Sciences, vol. 331, no. 4, pp. 219-225, 2006.

[11] C. M. Lee, P. T. Cirangle, and G. H. Jossart, "Vertical gastrectomy for morbid obesity in 216 patients: report of twoyear results," Surgical Endoscopy and Other Interventional Techniques, vol. 21, no. 10, pp. 1810-1816, 2007.

[12] A. G. Vargas-Ruiz, G. Hernández-Rivera, and M. F. Herrera, "Prevalence of iron, folate, and vitamin B12 deficiency anemia after laparoscopic Roux-en-Y gastric bypass," Obesity Surgery, vol. 18, no. 3, pp. 288-293, 2008.

[13] S. Gehrer, B. Kern, T. Peters, C. Christofiel-Courtin, and R. Peterli, "Fewer nutrient Deficiencies after laparoscopic sleeve gastrectomy (LSG) than after Laparoscopic Roux-Y-gastric bypass (LRYGB)-a prospective study," Obesity Surgery, vol. 20, no. 4, pp. 447-453, 2010.

[14] C. W. Howden, "Vitamin B12 levels during prolonged treatment with proton pump inhibitors," Journal of Clinical Gastroenterology, vol. 30, no. 1, pp. 29-33, 2000.

[15] J. I. Alvarez-Leite, "Nutrient deficiencies secondary to bariatric surgery," Current Opinion in Clinical Nutrition and Metabolic Care, vol. 7, no. 5, pp. 569-575, 2004.

[16] R. H. Clements, V. G. Katasani, R. Palepu et al., "Incidence of vitamin deficiency after laparoscopic Roux-en-Y gastric bypass in a university hospital setting," American Surgeon, vol. 72, no. 12, pp. 1196-1202, 2006.

[17] R. D. Bloomberg, A. Fleishman, J. E. Nalle, D. M. Herron, and S. Kini, "Nutritional deficiencies following bariatric surgery: whave we learned?" Obesity Surgery, vol. 15, no. 2, pp. 145154, 2005.

[18] H. A. Hakeam, P. J. O’Regan, A. M. Salem, F. Y. Bamehriz, and A. M. Eldali, "Impact of laparoscopic sleeve gastrectomy on iron indices: 1 year follow-up," Obesity Surgery, vol. 19, no. 11, pp. 1491-1496, 2009.

[19] G. Skroubis, G. Sakellaropoulos, K. Pouggouras, N. Mead, G. Nikiforidis, and F. Kalfarentzos, "Comparison of nutritional deficiencies after Roux-en-Y gastric bypass and after biliopancreatic diversion with Roux-en-Y gastric bypass," Obesity Surgery, vol. 12, no. 4, pp. 551-558, 2002.

[20] E. O. Aarts, I. M. C. Janssen, and F. J. Berends, "The gastric sleeve: losing weight as fast as micronutrients?" Obesity Surgery, vol. 21, pp. 207-211, 2011. 


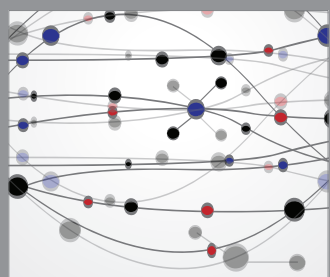

The Scientific World Journal
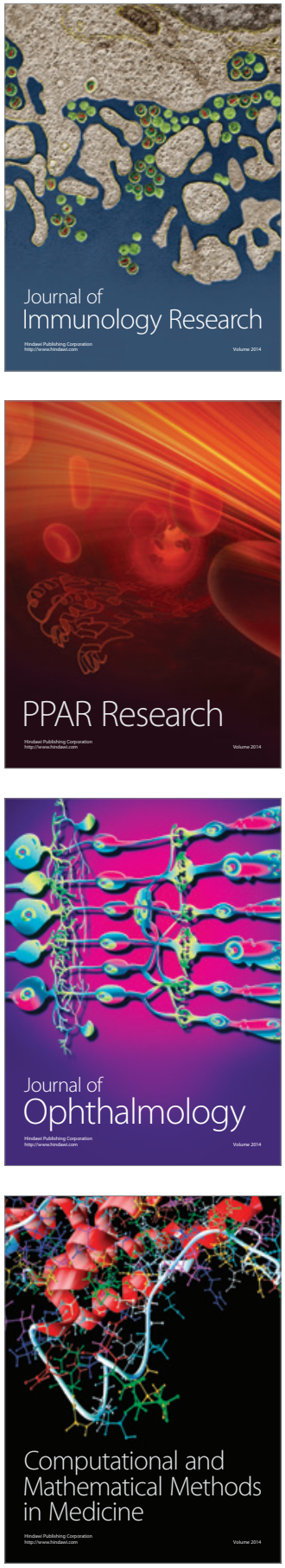

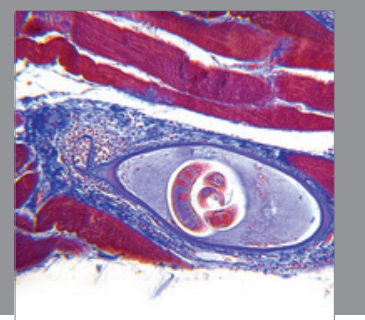

Gastroenterology

Research and Practice
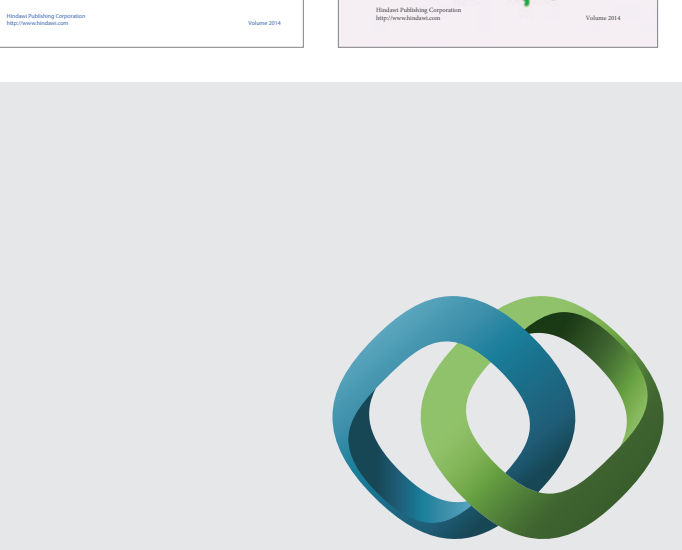

\section{Hindawi}

Submit your manuscripts at

http://www.hindawi.com
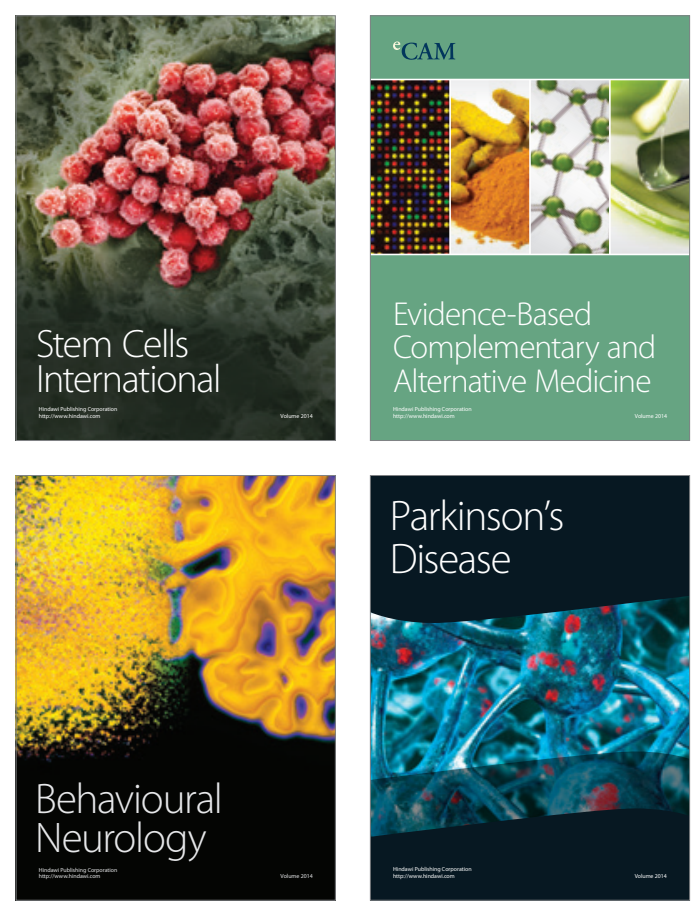

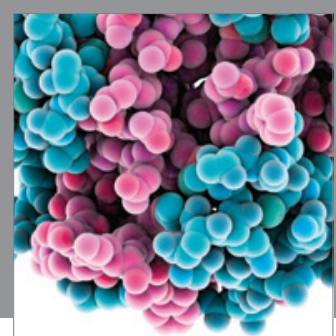

Journal of
Diabetes Research

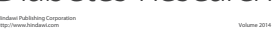

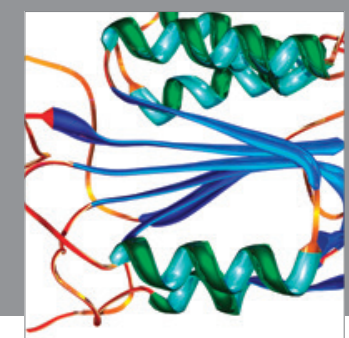

Disease Markers
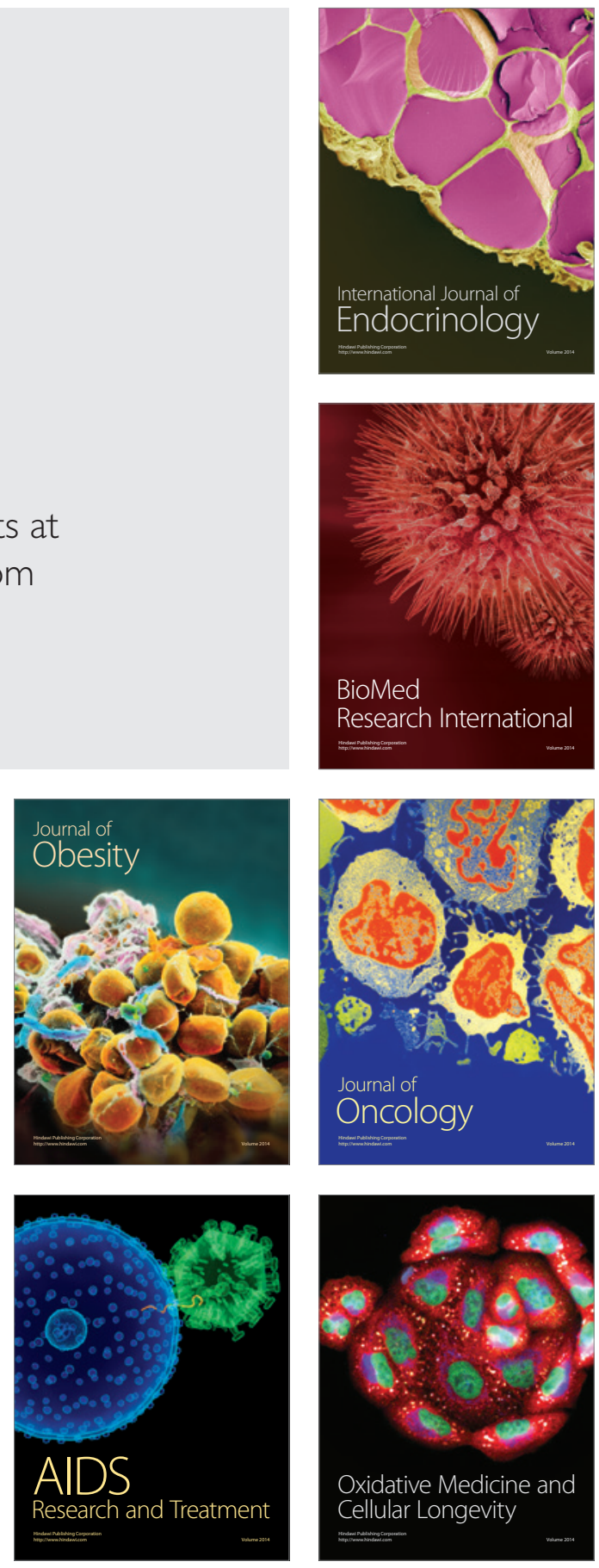